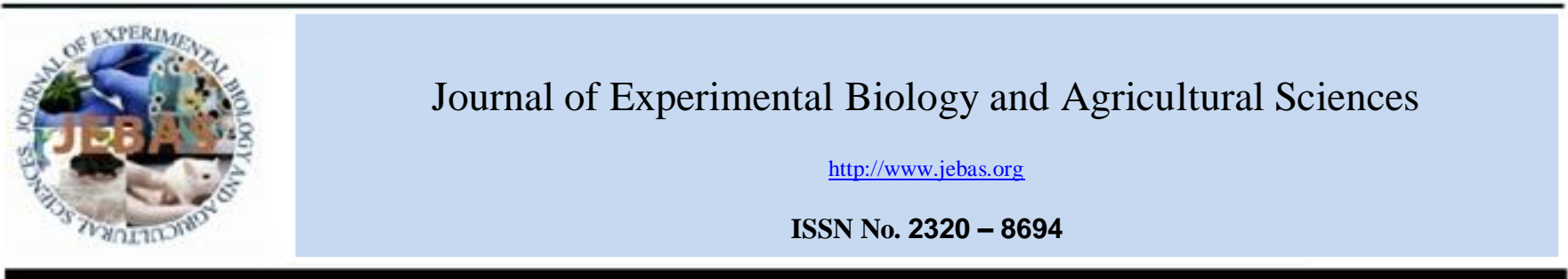

\title{
DEVELOPMENT AND APPLICATION OF Pasteurella multocida SEROTYPE A:1 WHOLE CELL BASED COAGGLUTINATION TEST (CAT) FOR THE RAPID DETECTION OF FOWL CHOLERA CAUSING ORGANISMS
}

\section{Stanzin Zadon ${ }^{1}$, Vinod Kumar Chaturvedi ${ }^{2}$, Praveen Kumar Gupta ${ }^{3}$, Varsha Paladan ${ }^{4}$, Perumal Nanda Kumar ${ }^{5}$}

\footnotetext{
${ }^{1,4}$ Division of Bacteriology \& Mycology, Indian Veterinary Research Institute, Izatnagar, U.P. 243122, India

${ }^{2}$ Principal Scientist, Division of Biological Products, Indian Veterinary Research Institute, Izatnagar, U.P. 243122, India

${ }^{3}$ Principal Scientist, Division of Veterinary Biotechnology, Indian Veterinary Research Institute, Izatnagar, U.P. 243122, India

${ }^{5}$ Division of Biochemistry, Indian Veterinary Research Institute, Izatnagar, U.P. 243122, India
}

Received - October 21, 2017; Revision - November 01, 2017; Accepted - December 16, 2017

Available Online - December 27, 2017

DOI: http://dx.doi.org/10.18006/2017.5(6).767.773

\author{
KEYWORDS \\ Pasteurella multocida \\ Coagglutination test \\ Fowl cholera \\ Diagnosis \\ Microorganism
}

\begin{abstract}
Pasteurella multocida whole cell antigen based coagglutination test was optimized in the laboratory for the specific and sensitive identification of bacteria causing fowl cholera in a simple and cost effective manner. The test showed $100 \%$ specificity and sensitivity up to $3.4 \times 10^{6}$ formalinized bacterial cells. For testing stability, sensitized coagglutination test reagents were stored at $4^{0} \mathrm{C}$ for $1-4$ months was subjected to reactions with inactivated P. multocida type A:1, A:3 and A:4 and non Pasteurella cultures at the end of each month. The optimized test also detected P. multocida type A:1, A:4 in experimentally infected birds $(n=10)$ indicating the potential application of the reagent to detect all possible somatic types of A capsular type which are etiological agents of Fowl cholera. P.multocida type B:2 experimentally infected mice $(n=4)$ tissues also showed coagglutination with the reagent exemplify its wider applicability in field diagnosis.
\end{abstract}

* Corresponding author

E-mail: vkchaturvedi@mail.com (Vinod Kumar Chaturvedi)

Peer review under responsibility of Journal of Experimental Biology and Agricultural Sciences.

Production and Hosting by Horizon Publisher India [HPI] (http://www.horizonpublisherindia.in/).

All rights reserved.
All the article published by Journal of Experimental Biology and Agricultural Sciences is licensed under a Creative Commons Attribution-NonCommercial 4.0 International License Based on a work at www.jebas.org.

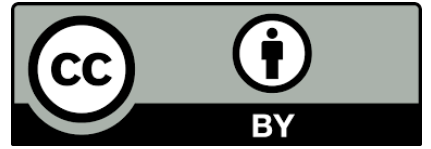




\section{Introduction}

Fowl cholera (FC) is a septicaemic disease of domestic and wildfowl caused by Pasteurella multocida serotype A:1, A:3, A:4 (David et al.,1991; Christensen \& Bisgaard 2000; Singh et al., 2014).The disease causes heavy economic losses to the poultry industry as its affects all ages of birds, however, chickens less than 16 weeks of age are rather resistant. The economic losses in chicken and turkey breeders encompasses in terms of morbidity (Akhtar et al., 2016) and high mortality (18-21\%) especially in broiler breeders (Kapetanov et al., 2000) laying flocks (Rhoades \& Rimler, 1987, Wang et al., 2009), low production of hatching eggs (15-20\%) and reduction of fertility (Kapetanov et al., 2000). Further, within a flock the healthy carrier and infected wild birds can favour the transmission of infection (Glisson et al., 2003). Therefore early diagnosis and management of such diseases are essential for the prevention and profitable poultry farming. Traditionally, the isolation and identification of the organisms using selective media is being used for standard diagnosis in the laboratory (Glisson et al., 2003, Cheesbrough, 2006).

The other alternative strategy includes use of molecular techniques. Of the various molecular methods, PCR is mainly used for the definite diagnosis of fowl cholera (Sellyei et al., 2008, Mohamed et al., 2012), as it is specific, rapid and simple (Panna et al., 2015). These two basic strategies of clinical diagnosis demands costly, sophisticated equipments and highly skilled human resource. Thus, these procedures are difficult for large scale diagnosis and may lack sensitivity under sensitivity under field conditions. Therefore, development of simple, accurate, specific, rapid and cost-effective diagnostic methods is of high priority for fowl cholera diagnosis especially in the countries where the disease is endemic.

The co-agglutination test (CAT) appears to be valuable and simple test that could fulfill these requirements which is a sensitive test for screening of infectious diseases. This test can detect $P$. multocida with high specificity in the form of visible clumps of agglutinations on a glass slide with unaided eye or an ordinary hand lens for better visibility. Therefore the present study was aimed to develop CAT for rapid and specific detection of $P$. multocida type A:1, A:3 and A:4 causing Fowl cholera.

\section{Materials and Methods}

\subsection{Bacterial cultures}

P. multocida serotype A:1, A:3 and A:4 were obtained from Type Culture Laboratory, Division of Biological Standardization, IVRI (Indian Veterinary Research Institute) and used for optimization of CAT. Staphylococcus aureus Cowan I strain was used for the preparation of CAT reagent. The other bacteria used in the present study and their sources are given in Table 1.

\subsection{Animals}

Four guinea pigs and four mice (Healthy) were procured from Laboratory Animal Resource section, IVRI and maintained under standard conditions of nutrition and management. The animal

Table 1 Used bacterial strains and their sources

\begin{tabular}{|cll|}
\hline S. No & Bacteria & Source \\
\hline 1 & Bacillus anthracis Sterne's strain & Type Culture Laboratory, Division of Biological Standardization, IVRI, Izatnagar \\
\hline 2 & Staphylococcus aureus & Type Culture Laboratory, Division of Biological Standardization, IVRI, Izatnagar \\
\hline 3 & Pasteurella multocida type B:2 & Division of Biological Standardization, IVRI, Izatnagar \\
\hline 4 & Mycoplasma & National Referral laboratory on Mycoplasma, IVRI, Izatnagar \\
\hline 5 & Salmonella Pullorum & National Salmonella Centre, IVRI, Izatnagar \\
\hline 6 & Salmonella Typhimurium & National Salmonella Centre, IVRI, Izatnagar \\
\hline 8 & Brucella abortus & Brucella Laboratory, B.P. Division, IVRI, Izatnagar \\
\hline 9 & Leptospira icterohaemorrhagia & National Leptospira laboratory, IVRI, Izatnagar \\
\hline 10 & E.coli & H.S Laboratory, B.P Division, IVRI, Izatnagar \\
\hline
\end{tabular}


ethics committee of IVRI, Deemed University approved this study.

\subsection{Preparation of $P$. multocida type A:1 antigen}

P. multocida type A:1 was cultured in $5 \mathrm{ml}$ Casein Sucrose Yeast (CSY) broth tubes for 18 hours at $37^{\circ} \mathrm{C}$. After examining the growth for purity and identity, $3 \mathrm{ml}$ of the culture was used for sowing Roux flasks containing 120-150 ml of CSY agar. The growth was harvested with the help of 10-20 $\mathrm{ml}$ of normal saline solution from each flask after incubation at $37^{\circ} \mathrm{C}$ for 24 hours, purity and identity was rechecked. The pooled growth having $3.4 \times 10^{9} \mathrm{cfu} / \mathrm{ml}$ was then inactivated with $0.5 \%$ formalin followed by incubation for 24 hours at $37^{\circ} \mathrm{C}$. Each pooled growth was stored for a week at $4{ }^{0} \mathrm{C}$. The harvests were adjusted to $\mathrm{Mc}$ Farlands tube no.7.

\subsection{Preparation of anti- P.multocida type A:1 hyperimmune sera for coating on to CAT reagent}

Four guinea pigs (Healthy) were immunized intramuscularly each with $0.5 \mathrm{ml}$ of whole cell type A:1 antigen (section 2.3) emulsified in Freund's complete adjuvant. Booster doses were given with 0.5 $\mathrm{ml}$ antigen at days 14, 21 and 42 with Freund's incomplete adjuvant. After 5 days of the last injection, agglutination titre was found as 640 by standard tube agglutination test (STAT). Animals were finally bled at 7 days of the last injection; serum was separated and stored at $-20^{\circ} \mathrm{C}$.

\subsection{Adsorptions of anti-P.multocida A:1 sera with cross} reacting bacteria

The most commonly cross reacting bacteria with $P$. multocida type A:1 i.e E. coli and Salmonella Pullorum were pre-adsorbed to anti-type A:1 sera by mixing $50 \mu \mathrm{l}$ each of heat killed E. coli and Salmonella Pullorum culture (in NSS) with $120 \mu 1$ of serum. The resultant solution was incubated at $37^{\circ} \mathrm{C}$ for 1 hour followed by centrifugation at $10,000 \mathrm{rpm}$ for 3 minutes. Then the upper supernatant was used for coating with $S$. aureus Cowan I strain.

\subsection{Preparation of CAT reagent}

CAT reagents were prepared as described by Joshi \& Shakya (1997) with minor modifications. Briefly, the S. aureus Cowan I strain were grown in $10 \mathrm{ml}$ of nutrient broth from the master plate and were incubated at $37^{\circ} \mathrm{C}$ for 24 hours. After testing for purity and sterility, $3 \mathrm{ml}$ of the culture was used for sowing Roux flasks each containing $120-150 \mathrm{ml}$ of brain heart infusion (BHI) agar. After incubation at $37^{\circ} \mathrm{C}$ for 24 hours, the pure growth was harvested with the help of normal saline solution $(10-20 \mathrm{ml})$ from each flask and examined for its purity followed by addition of a dye $\left(0.1 \%\right.$ triphenyl tetrazolium chloride) into it and kept at $37{ }^{\circ} \mathrm{C}$ for 30 minutes. Subsequently, formalin $(0.5 \%)$ was added to the culture and kept at $80{ }^{\circ} \mathrm{C}$ for 3 hours for complete inactivation of the organisms. The coloured cells were then pelleted by centrifugation $(2,500 \mathrm{rpm}$ for 10 minutes $)$ and washed thrice with PBS ( $\mathrm{pH} 7.4$ ). Finally, the cells were adjusted to $10 \%(\mathrm{w} / \mathrm{v})$ concentration with PBS and stored at $4^{0} \mathrm{C}$.

\subsection{Sensitization of coagglutination reagent with anti-type A:1 hyperimmune serum}

For sensitization, equal volume of $10 \%$ suspension of S. aureus Cowan I strain and anti-type A:1 hyperimmune serum (heat inactivated at $56^{\circ} \mathrm{C}$ for $30 \mathrm{~min}$ ) were mixed thoroughly by vortexing for 1 minute and allowed to react for 2.5 hours at $37^{\circ} \mathrm{C}$ in shaker incubator. The coated cells were then washed by centrifugation (PBS- 2 times) and resuspended in PBS (pH 7.4) as $10 \%(\mathrm{w} / \mathrm{v})$ suspension. Sodium azide $(0.1 \%)$ was added to a final concentration of $1 \%$ and the reagent was stored at $4^{0} \mathrm{C}$ until used. For optimization, the reaction of coated cells with type A:1 hyperimmune sera was done by evaluating of reaction time (30 $\min , 60 \mathrm{~min}, 2 \mathrm{hr}$ and $2.5 \mathrm{hr}$ ), temperature $\left(25^{\circ} \mathrm{C}, 30^{\circ} \mathrm{C}\right.$ and $\left.37^{\circ} \mathrm{C}\right)$, and buffer $\mathrm{pH}(7.0,7.2$ and 7.4). Finally the above conditions were found to be optimum.

\subsection{Coagglutination test (CAT)}

P. multocida type A:1, A:3, A:4 were grown in $5 \mathrm{ml}$ of casein sucrose yeast (CSY) broth by incubating at $37^{\circ} \mathrm{C}$ for 18 hour (stationary cultures) and then inactivated by formalization. For sterility checking, the obtained culture were subcultured into $5 \mathrm{ml}$ CSY broth tube and incubated at $37^{\circ} \mathrm{C}$ for 24 hours.

To perform CAT, 10 ul of anti-type A:1 serum coated CAT reagent and inactivated P.multocida type A:1, A:3, A:4 culture were mixed on separate glass slide along with each negative control (PBS) and observed for 30 seconds to 1 minute for the appearance of agglutination.

\subsection{Specificity evaluation}

Three major avian species of $P$. multocida (type A:1, A:3, A:4), $P$. multocida type B:2 and 10 non-Pasteurella bacteria (Table no. 1) were subjected to co-agglutination test to check the specificity of the reaction. Briefly, each bacterium was grown in $5 \mathrm{ml}$ of casein sucrose yeast (CSY) broth and incubated at $37^{\circ} \mathrm{C}$ for 18 hour. The CFU count of each culture was done by spread plate method (Heritage et al., 1996). The cultures were then inactivated by formalization. For CAT, $10 \mu \mathrm{l}$ of each formalized culture was tested for agglutination with equal volume of sensitized CAT (anti-type A:1 sera coated) reagent within 15-30 seconds. 


\subsection{Sensitivity evaluation}

Detection limit of a CAT was done by serial 10-fold dilutions of inactivated cultures ( $P$. multocida A:1, A:3, A:4) were prepared in PBS and $10 \mu \mathrm{l}$ from each dilution was used for CAT. The concentrations of each diluted solution were determined by CFU/ml (Heritage et al., 1996). The highest dilution showing distinct agglutination was noted.

\subsection{Stability testing}

For testing stability, sensitized CAT reagent stored at $4{ }^{\circ} \mathrm{C}$ for $1-4$ months was subjected to reactions with inactivated $P$. multocida serotype A:1, A:3 and A:4 and other cultures at the end of each month.

\subsection{Evaluation of repeatability}

The repeatability of CAT was tested at one month interval for 1-4 months by the same lot of sensitized reagent. The specificity and sensitivity were also assayed with the CAT reagents sensitized after storage of the hyperimmune serum at $-80{ }^{\circ} \mathrm{C}$ for 4 months.

\subsection{Experimental infection study}

Next, we applied the optimized CAT for the detection of $P$. multocida type A:1 and A:4 in experimentally infected birds $(\mathrm{n}=10)$ and Pasteurella type B:2 in experimentally infected mice $(n=5)$. Postmortem were done and lungs, liver, spleen, heart, heart blood and intestinal contents were collected from all the dead birds and dead mice, finally these samples were tested with the CAT reagent. Simultaneously, the confirmation of the Pasteurella type A:1, A:4 and B:2 was done by isolation on fresh blood agar plates and confirmation of reisolated culture was also done by CAT.

\section{Results}

\subsection{Coagglutination test}

In the proper CAT, the cells were uniformly distributed and agranular in the negative reaction (Figure 1-1), whereas positive reaction, indicating the presence of bacteria that can cause fowl cholera, had a granular appearance with clumps of cells within 1530 seconds (Figure 1-2).

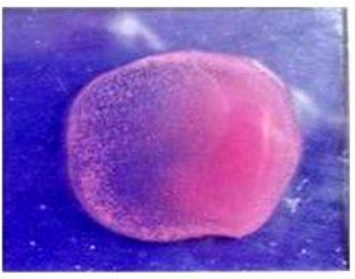

1

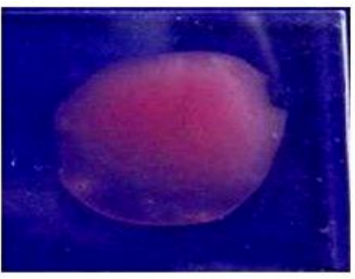

2
Figure 1 Coagglutination test with inactivated bacterial cultures

(1) Positive agglutination with P. multocida serotype A:1 culture

(2) Negative agglutination with P. multocida serotype A:1 culture

\subsection{Specificity}

The specificity testing showed that the optimized test was very specific for $P$. multocida type A:1, A:3, A:4 since anti-type A:1 sera was pre-adsorbed with other Gram negative bacteria such $E$. coli and Salmonella Pullorum which may cross react with Pasteurella multocida capsular type A in upper respiratory tract of birds (Figure 2-1,2) and the reaction did not show cross reactivity with none of the 10 non-Pasteurella bacteria even at 100 times higher concentrations than the detection limit of the test for $P$. multocida A:1,A:3 and A:4 cells.

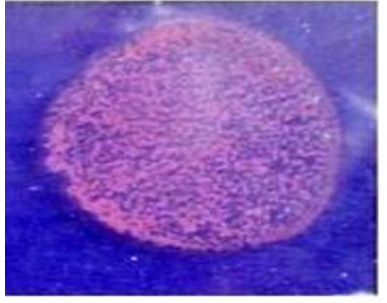

1

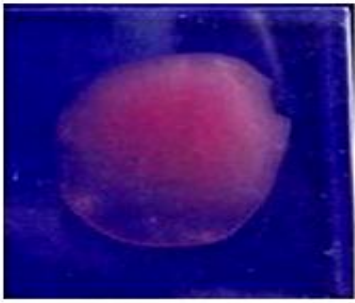

2
Figure 2 Specificity evaluation of CAT

(1) CAT with adsorbed whole cell type A:1 sera

(2) control negative

\subsection{Sensitivity}

The sensitivity evaluation (Figure 3-1,2,3) revealed that minimum $3.4 \times 10^{6} \mathrm{CFU} / \mathrm{ml}$ of P. multocida (A:1, A:3, A:4) was sufficient to give clear agglutination (Fig 3-3) whereas $3.4 \times 10^{5} \mathrm{CFU} / \mathrm{ml}$ of $P$. multocida (A:1, A:3, A:4) did not show visible agglutination (Figure 3-4).

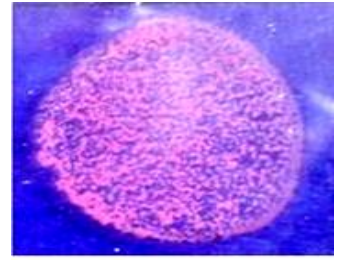

1

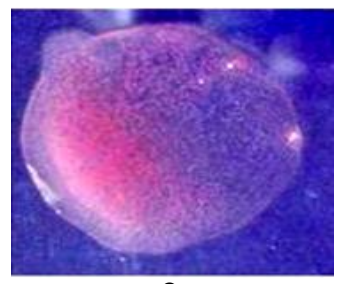

3

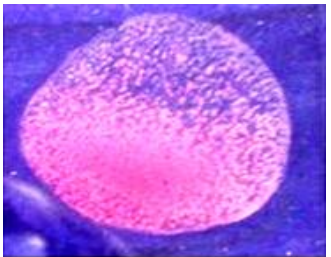

2

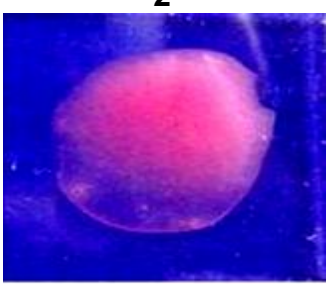

4
Figure 3 Sensitivity evaluation of CAT

(1) CAT with $3.4 \times 10^{8} \mathrm{CFU}$ of $P$. multocida serotype A: 1 cells

(2) CAT with $3.4 \times 10^{7}$ CFU of $P$. multocida serotype A:1 cells

(3) CAT with $3.4 \times 10^{6} \mathrm{CFU}$ of $P$. multocida serotype A:1 cells

(4) CAT with $3.4 \times 10^{5} \mathrm{CFU}$ of $P$. multocida serotype A:1 cells

Journal of Experimental Biology and Agriculture Science http://www.jebas.org 


\subsection{CAT on clinical samples}

Application of the developed CAT was assessed on samples from birds of known infectious status to evaluate its potential use under field conditions. Out of 10 samples used for detection of the fowl cholera from experimentally infected animals, all samples were showing a very clear cut positive reaction. Among the tissue samples, intestinal content was showing very quick and distinct agglutination (within few seconds) followed by heart blood, heart tissue, spleen, lungs and liver (Figure 4-1,2,3,4,5,6). Whereas no cross reaction was found in the samples of control birds. To confirm the CAT result, $P$. multocida was isolated on fresh blood agar and then checked by PCR as well.

Furthermore, CAT result was also showing positive reaction with P. multocida serotype B:2 samples from experimentally infected mice $(n=4)$. Among the different tissues collected from mice, spleen was showing very quick result followed by heart tissue, heart blood, liver, lungs and blood in PBS (Figure 5$2>4>5>1>3>6$ ). However, no cross reaction was seen from the samples collected from control birds. The tissue samples of A: 4 birds similarly showed positive reaction in coagglutination test.

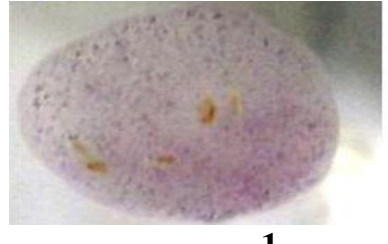

1

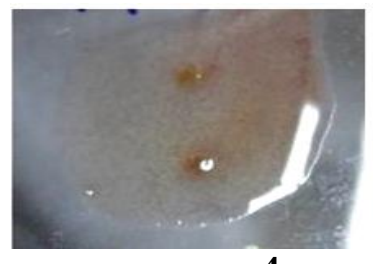

4

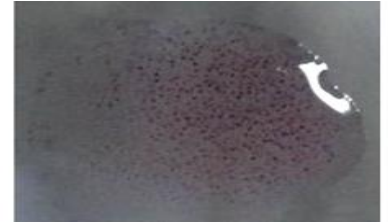

2

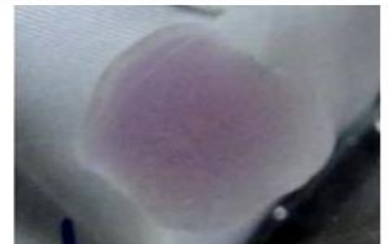

5

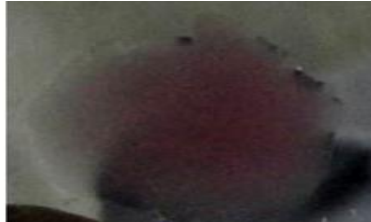

3

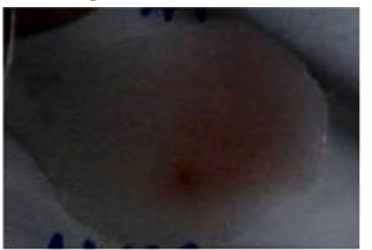

6

Figure 4 CAT using experimental samples of birds
(1) CAT with intestinal content
(2) CAT with heart blood
(3) CAT with heart tissue

(4) CAT with spleen

(5) CAT with lungs

(6) CAT with liver
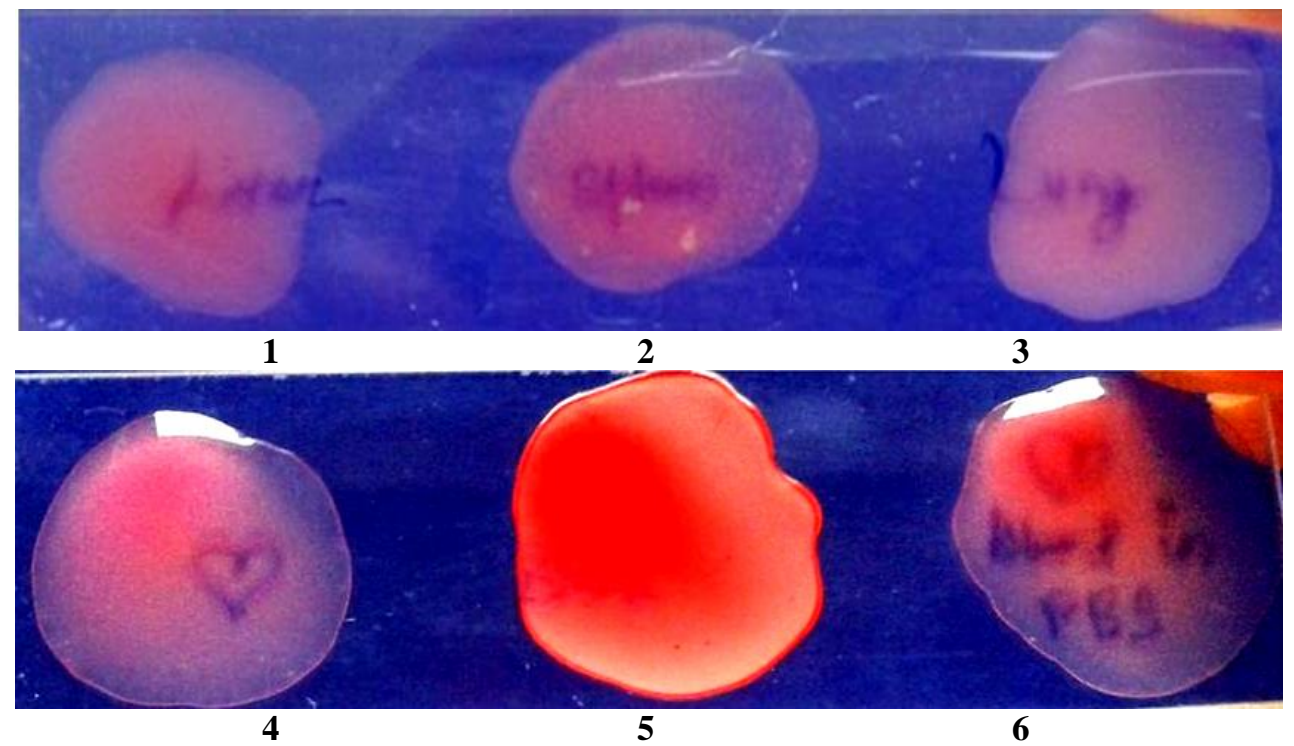

Figure 5 CAT using experimental samples of mice
(1) CAT with Liver tissues
(2) CAT with spleen tissues,
(3) CAT with lungs tissues
(4) CAT with heart blood
(5) CAT with heart tissues
(6) CAT with blood in PBS

Journal of Experimental Biology and Agriculture Science http://www.jebas.org 


\section{Discussion}

Fowl cholera is highly fatal form of avian P. multocida that cause economic losses to poultry producer (Akhtar et al., 2016). Accurate diagnosis of the disease is mainly done by confirmation by PCR targeting capsular gene Cap specific for P. multocida (Akhtar et al., 2016; Wei et al., 2017). Although PCR is an essential tool in the research laboratory, the success of the method usually depends on inhibitors-free samples (Ribeiro \& Araujo, 2009). PCR may also help to identify carrier animals within flocks (Christensen \& Bisgaard, 2000; Townsend et al., 2001). Thus, the use of PCR for molecular diagnosis is accepted as the standard method for detecting nucleic acids from various major infectious agents using different sampling techniques. Still, it cannot be used for large scale field diagnosis as the laboratory facilities required for the purpose cannot be extended at farmers' door. The other methods of diagnosis like direct demonstration of the etiological organism in the blood smear or isolation of the organism and characterization of organism are more time consuming and diagnosis demands further confirmation. The confirmatory diagnostic test should encompass the confirmatory detection of capsular antigens of $P$. multocida in the sample. This can be done best by the use of primary binding tests with detection of binding antibody. These primary binding tests are again having limitations of sophisticated facility and cannot be adopted at farmers' door.

In that direction, the coagglutination test employing formalinfixed $S$. aureus cells sensitized with polyclonal mice antiserum appears a suitable alternative option in this direction. The dynamics of test process lies in the binding of the antibodies to protein A on the surface of staphylococcal cells via Fc portion, leaving Fab portion free (Ribeiro \& Araujo, 2009). Further, when these antibody-coated cells are mixed with homologous antigen, the Fab portion specifically binds to the antigen, causing the cells to coagglutinate (Bootland \& Leong, 1992). The worth mentioning feature of the test rests in that there is direct detection of the pathogen since agglutination tests do not require any costly equipment or skilled personnel and do not cost much because only few microliter of $S$. aureus stained coated sera and glass slide are required for each test. Moreover time required to see the result of the test is only 1 minute with ones naked eye.

In the study, the development and the application of the coagglutination test had been made for diagnosis fowl cholera in terms of analytical sensitivity and specificity with the pure culture of different capsular types of P. multocida and the other possible common bacterial pathogens which are either cross reacting or associated with the diseases in poultry. The results of the study showed high specificity and sensitivity. The suitability of test was further validated by testing the experimentally generated samples and the test was found to have its suitability in the diagnosis of fowl cholera.
The findings of study further corroborated the earlier application of this test for the diagnosis of bacterial infections such as Staphylococcal infections, Haemophilus parasuis, enterotoxigenic Escherichia coli and Bacillus anthracis (Bootland \& Leong, 1992; Del Rio et al., 2003; Varshney et al., 2007, Sumithra et al., 2013) and viral infections such as FMD, Rota virus and Adeno virus, Parvo virus (Montassier et al., 1994; Peret et al., 1995; Singh et al., 1998; Ribeiro \& Araujo, 2009) and also for several bacterial enterotoxins. The suitability of test was further ascertained by the observation that it could be applied on the killed culture of $P$. multocida. Therefore, if sample transportation in formalin is desired, it can be done without affecting the diagnostic potential of the test. Similar application had been described with formalin treated cultures proved the suitability of test with killed culture (Sumithra et al., 2013). As the optimized test can be performed with inactivated culture, hence it would reduce the risk of handling live organisms in the laboratory.

In gist, due to its high specificity and adequate sensitivity when performed on clinical samples from different organs, it can be used as a diagnostic test at a flock level. A fully developed CAT diagnostic test may make fowl cholera detection easier, faster and bring significant economic benefits in the poultry industries. Applicability of this test is not only to fowl cholera but to other infectious diseases of animals and humans wherever agglutination test is applicable.

\section{Conclusion}

In conclusion, this article presents the first report of a coagglutination test for the faster and easier identification of bacteria causing avian pasteurellosis without compromising specificity and sensitivity through the detection of whole cell $P$. multocida serotypes A:1, A:3, A:4 antigen in a low cost and simple manner.

\section{Acknowledgements}

The authors acknowledge with thanks to Director, Indian Veterinary Research Institute, Izatnagar for providing facilities in the laboratory.

\section{Conflict of Interest}

Authors would hereby like to declare that there is no conflict of interests that could possibly arise.

\section{References}

Akhtar M, Rahman MT, Ara MS, Rahman M, Nazir KHMNH, Ahmed S, Hossen ML, Rahman MB (2016) Isolation of 
Pasteurella multocida from chickens, preparation of formalin killed fowl cholera vaccine, and determination of efficacy in experimental chickens. Journal of Advanced Veterinary and Animal Research 3: 45-50.

Bootland LM, Leong JA (1992) Staphylococcal coagglutination, a rapid method of identifying infectious hematopoietic necrosis virus. Applied and Environmental Microbiology 58: 6-13.

Cheesbrough M (2006) Biochemical tests to identify bacteria. In: Cheesbrough $M(\mathrm{Ed})$. District laboratory practice in tropical countries, Part 2. 2nd Edn, Cambridge University Press, UK; 7: 62-70.

Christensen JP, Bisgaard M (2000) Fowl cholera. Revue scientifique et technique Office International Epizootic 19: 626637.

David WH, Carpenter TE, Snipes KP, HirshDC, McCapes (1991) Control study of Fowl Cholera outbreaks in meat turkeys in California from August 1985 through July 1986. American Journal of Veterinary Research 52: 212-216.

Del Rio ML, Gutierrez CB, Ferri EFR (2003) Value of indirect hemagglutination and coagglutination tests for serotyping Haemophilus parasuis. Journal of Clinical Microbiology 41 : 880-882.

Glisson JR, Hofacre CL, Christensen JP (2003) Fowl cholera. In: Saif YM, Fadly AM, Glisson JR, McDougald LR, Nolan LK, Swayne DE (Eds.), Diseases of poultry, 11th ed., Iowa State University Press, Ames, IA, Pp. 658-676..

Heritage J, Evans EGE, Killington RA (1996) Introductory Microbiology. Cambridge University Press, Cambridge.

Joshi RK, Shakya S (1997) Rapid diagnosis of fowl pox with coagglutination assay. Tropical Animal Health and Production 29:147-150

Kapetanov MR, Kapetanov L, Suvajdzic, Velhner M (2000) Cholera caused by Pasteurella in breeder flocks. Zivinarstvo 35: 211-213.

Mohamed MA, Mohamed MW, Ahmed AI, Ibrahim AA, Ahmed MS (2012) Pasteurella multocida in backyard chickens in Upper Egypt: Incidence with polymerase chain reaction analysis for capsule type, virulence in chicken embryos and antimicrobial resistance. Veterinaria Italiana 48: 77-86.

Montassier HJ, Araujo JP, Pinto AA (1994) Rapid coagglutination test for the detection and typing of Foot and Mouth Disease virus. Journal of Virological Methods 50: 29-42.

Panna SN, Nazir KHMNH, Rahman MB, Ahamed S, Saroare MG, Chakma S, Kamal T, Majumder UH (2015) Isolation and molecular detection of Pasteurella multocida Type A from naturally infected chickens, and their histopathological evaluation in artificially infected chickens in Bangladesh. Journal of Advanced Veterinary and Animal Research 2: 338-345.

Peret TCT, Durigon EL, Candeias JMG, Stewien KE, Candeias JAN (1995) A combined staphylococcal coagglutination assay for rapid identification of rotavirus and adenovirus (COARA). Journal of Virological Methods 52: 265-272.

Rhoades KR, Rimler RB (1987) Capsular groups of Pasteurella multocida isolated form avian hosts. Avian Diseases 31: 895-898.

Ribeiro MCM, Araujo JP (2009) Coagglutination for viral DNA preparation of canine parvovirus for molecular diagnosis. Journal of Virological Methods 161: 305-307.

Sellyei B, Varga Z, Ivanics E, Magyar T (2008) Characterisation and comparison of avian Pasteurella multocida strains by conventional and ERIC-PCR assays. Acta Veterinaria Hungarica 56: 429-440.

Singh R, Remington B, Blackall P, Turni C (2014) Epidemiology of Fowl Cholera in free range broilers. Avian Diseases 58: 124128.

Singh BR, Yadav RC, Singh SP, Sharma VD (1998) Coagglutination test: a simple and rapid immunodiagnostic test for parvovirus infection in dogs. Indian Journal of Experimental Biology 36: 622-624.

Sumithra TG, Chaturvedi VK, Gupta PK, Sunita SC, Rai AK, Kutty MVH ( 2013) Development of a simple and rapid method for the specific identification of organism causing anthrax by slide latex agglutination. Letters to Applied Microbiology 58: 401 - 407.

Townsend KM, Boyce JD, Chung JY, Frost AJ, Adler B (2001) Genetic organization of Pasteurella multocida cap Loci and development of a multiplex capsular PCR typing system. Journal of Clinical Microbiology 39: 924-929.

Varshney BC, Ponnanna NM, Sarkar PA, Rehman P, Shah JH (2007) Development of a monoclonal antibody-based coagglutination test to detect enterotoxigenic Escherichia coli isolated from diarrhoeic neonatal calves. Journal of Veterinary Science 8: 57-64.

Wang C, Wu Y, Xing X, Hu G, Dai J, He H (2009) An outbreak of avian cholera in wild waterfowl in Ordos wetland, Inner Mongolia, China. Journal of Wildlife Diseases 45: 1194-1197.

Wei X, Wang Y, Luo R, Qian W, Sizhu S, Zhou H (2017) Identification and characterization of a protective antigen, PlpB of bovine Pasteurella multocida strain LZ-PM. Developmental and Comparative Immunology 71: 1-7. 